\title{
Formation of silver microbelt structures by laser irradiation of silver nanoparticles in ethanol
}

\author{
This article was published in the following Dove Press journal: \\ International Journal of Nanomedicine \\ 7 October 2011 \\ Number of times this article has been viewed
}

\author{
Reza Zamiri' \\ Azmi Zakaria ${ }^{1,2}$ \\ Mohd Shahril Husin' \\ Zaidan Abd Wahab' \\ Forough Kalaei Nazarpour ${ }^{3}$ \\ 'Department of Physics, Faculty of \\ Science; ${ }^{2}$ Advanced Materials and \\ Nanotechnology Laboratory, Institute \\ of Advanced Technology; ${ }^{3}$ nstitute of \\ Bioscience, Universiti Putra Malaysia, \\ Serdang, Selangor, Malaysia
}

Correspondence: Azmi Zakaria

Advanced Materials and Nanotechnology Laboratory, Institute of Advanced

Technology, Universiti Putra Malaysia, 43400 UPM Serdang, Selangor, Malaysia

$\mathrm{Tel}+\mathrm{I} 60389466650$

Fax + I 60389454454

Email azmizak@gmail.com
Abstract: In the present work, we prepared silver nanoparticles by laser ablation of pure silver plate in ethanol and then irradiated the silver nanoparticles using a $532 \mathrm{~nm}$ Q-switched $\mathrm{Nd}$ :YAG pulsed laser. Transmission electron microscopic images of the sample after irradiation clearly showed formation of big structures, such as microrods and microbelts in ethanol. The obtained microbelts had a width of about $0.166 \mu \mathrm{m}$ and a length of $1.472 \mu \mathrm{m}$. The reason for the formation of such a big structure is the tendency of the nanoparticles to aggregate in ethanol before irradiation, which causes fusion of the nanoparticles.

Keywords: nanomaterial, laser ablation, nanoparticles

\section{Introduction}

Metal nanoparticles with their wide range of applications, such as catalytic systems with optimized selectivity and efficiency, optical components, targeted thermal agents for exploitation in drug delivery and medical therapies, and surface-enhanced Raman spectral probing, have attracted research attention during the last decade. The size-dependent and shape-dependent properties of nanoparticles render them different from their corresponding bulk materials with macroscopic dimensions. Fabrication of metal nanoparticles by laser ablation of bulk plate in liquid media has been investigated intensively in recent research. ${ }^{1-4}$ The results of these studies have shown that laser beam irradiation onto metal nanoparticles causes fragmentation or fusion of the particles due to photothermal melting. ${ }^{5-9}$ Therefore, laser irradiation can be used to control the shape and size of particles. On the other hand, there are some reports about fabrication of nanonetworks and nanowire structures by laser ablation of solids in liquid media ${ }^{10,11}$ and laser irradiation of nanocolloids. ${ }^{12}$ For example, Tsuji et al have found that secondary laser irradiation of a nanocolloid in water can cause formation of a nanowire structure. According to their report, fusion of melted particles as a result of absorption laser beam is an acceptable interpretation of the formation of nanowire. There are reports from further researchers showing that particle aggregation before irradiation is an important factor for particle fusion. ${ }^{13,14}$ They have found that after laser light irradiation, agglomerated gold colloids become larger, but dispersed colloids become smaller. This means that when colloidal particles are well dispersed in liquid, only fragmentation of particles happens upon laser irradiation. In this study, we report the production of silver nanoparticles in ethanol used as a nonstabilizing medium for preparation of nanoparticles, and subsequent irradiation of the prepared nanoparticles to achieve large structures. 


\section{Methods}

Silver plate of high purity (99.99\%) from Sigma Aldrich (St Louis, MO) was ablated for 15 minutes in $10 \mathrm{~mL}$ of distilled water and ethanol in a $1 \times 2 \times 3 \mathrm{~cm}^{3}$ glass cell by a 1064 nsec-pulsed Q-switched Nd:YAG laser (Brilliant laser system) with a $5 \mathrm{nsec}$ pulse duration, a $10 \mathrm{~Hz}$ repetition rate, and $360 \mathrm{~mJ} /$ pulse energy to produce silver nanoparticles. The experimental apparatus used for laser ablation of metal plate has been described elsewhere. ${ }^{1-4}$ The beam was focused onto the target using a $25 \mathrm{~cm}$ focal length lens. The plate was then removed from the glass cell, and the silver nanoparticles were irradiated by another Q-switched Nd:YAG pulsed laser (SL400/SL800 system) of wavelength $532 \mathrm{~nm}$, duration $10 \mathrm{nsec}$, and pulse energy $60 \mathrm{~mJ}$ for 15 minutes. This second laser wavelength was used because it had previously been found that silver nanoparticles can effectively interact with this wavelength to become hot compared with $1064 \mathrm{~nm} .{ }^{15}$ The prepared samples were characterized using an ultravioletvisible double beam spectrometer (Shimadzu, Tokyo, Japan) and a transmission electron microscope (Hitachi H-7100).

\section{Results and discussion}

The ultraviolet-visible absorption spectra of silver nanoparticles inside ethanol before and 15 minutes after laser irradiation at a wavelength of $532 \mathrm{~nm}$ are presented in Figure 1. Here it can be seen that the surface plasmon peak shifts a little towards higher energy and the spectra width become a little narrower after laser irradiation. According to Mie theory, this shift corresponds to a decrement in particle size which originates from fragmentation of the nanoparticles by $532 \mathrm{~nm}$ laser. On the other hand, the decrease in spectra width is related to a decrease in the particle size distribution within the ethanol after irradiation.

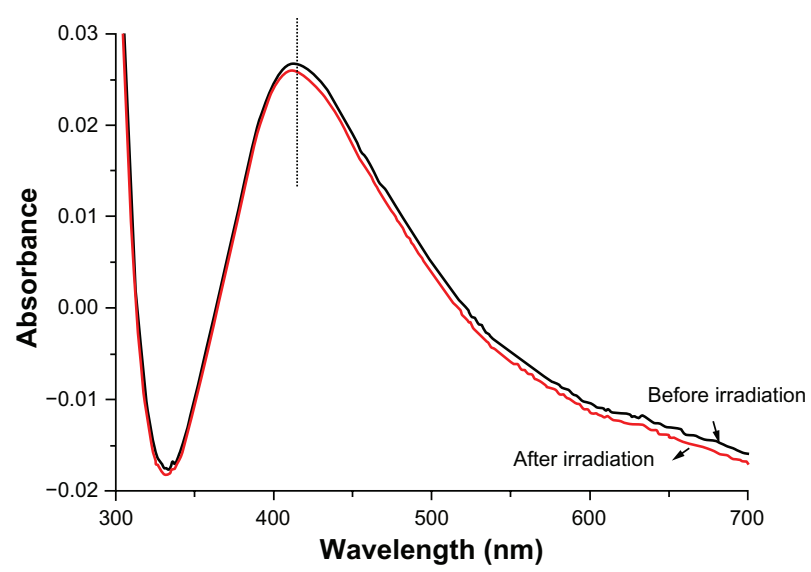

Figure I Ultraviolet-visible absorption spectra of silver nanoparticles inside ethanol before and after irradiation.
Figure 2 shows transmission electron microscopic images of silver nanoparticles inside water after 15 minutes of irradiation at $532 \mathrm{~nm}$. In Figure 2A and B, all the silver nanoparticles are interconnected with each other and form a network structure, while in Figure 2C, silver nanowire was formed. Thus, our results are in agreement with previous
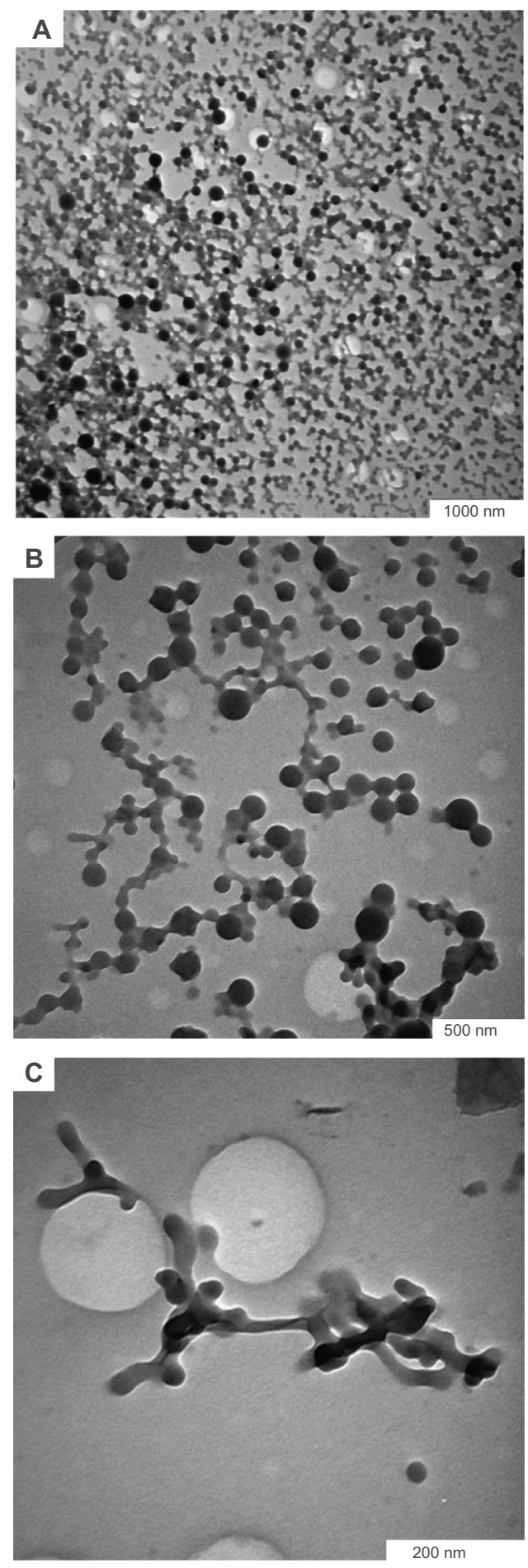

Figure 2 Formation of $(\mathbf{A})$ and $(\mathbf{B})$ network structures and (C) nanowire after irradiation of silver colloids in water. 
work by Tsuji et al, ${ }^{12}$ who produced nanowire in water by irradiation of silver colloid at $355 \mathrm{~nm}$, and explained that fusion of nanoparticles that had been photothermally melted by laser irradiation was a possible mechanism for formation of the nanowire.

On the other hand, it has also been reported that particle aggregation before irradiation is an important factor causing
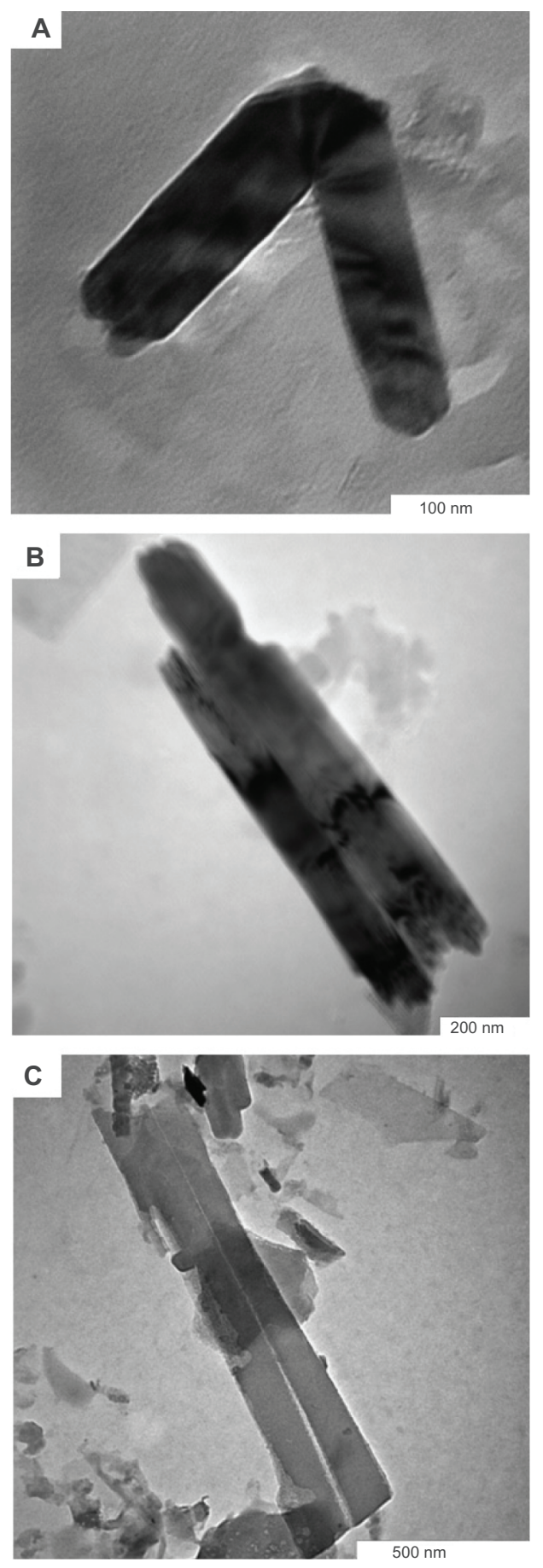

Figure 3 Formation of (A) bended microrod, (B) microrod, and (C) microbelt structure after irradiation of silver colloids in ethanol. fusion of nanoparticles. ${ }^{13,14}$ Previous research has shown that preparation of nanoparticles in ethanol using $1064 \mathrm{~nm}$ laser is less stable than when the procedure is performed in water. ${ }^{16}$ The main reason for this instability is related to the dipole moments of the surrounding molecules. In the case of ethanol, the asymmetric charge distribution on the surface of the nanoparticles causes dipole-dipole interaction and can lead to linear assembly. ${ }^{17}$ Due to Brownian motion of the particles in solution, the particles attract each other and become aggregated because of weak repulsive force and dipole-dipole interactions. Therefore, in this experiment, we used ethanol as a medium for preparation of silver nanoparticles to increase agglomeration of nanoparticles before irradiation. Figure $3 \mathrm{~A}-\mathrm{C}$ shows transmission electron microscopic images of silver colloid in ethanol after irradiation at $532 \mathrm{~nm}$.

As is clear from Figure 3, the structures obtained in ethanol have a different shape to those in water. Figure $3 \mathrm{~A}$ and $\mathrm{B}$ show formation of large bent nanorods and straight microrods, and formation of microbelts is very clear in Figure 3C. The microbelts obtained had a width of $0.166 \mu \mathrm{m}$ and a length of $1.472 \mu \mathrm{m}$. Therefore, the results show that aggregation of particles before irradiation can cause formation of large structures, such as microbelts.

\section{Conclusion}

In summary, we have irradiated silver colloids in water and ethanol by laser with a wavelength of $532 \mathrm{~nm}$. Our results show formation of nanowire in water after irradiation, while in ethanol we obtained larger structures, such as microrods and belts. The formation of such large structures may be due to aggregation of the nanoparticles in ethanol before irradiation, which causes fusion of the nanoparticles.

\section{Acknowledgment}

The authors gratefully acknowledge the financial support by Ministry of Higher Education Malaysia through FRGS Project \#01-04-10-864FR.

\section{Disclosure}

The authors report no conflicts of interest in this work.

\section{References}

1. Zamiri R, Azmi BZ, Darroudi M, et al. Preparation of starch stabilized silver nanoparticles with spatial self-phase modulation properties by laser ablation technique. Appl Phys A. 2011;102:189-194.

2. Darroudi M, Ahmad MB, Zamiri R, et al. Preparation and characterization of gelatin mediated silver nanoparticles by laser ablation. J Alloys Compd. 2011;509:1301-1304. 
3. Zamiri R, Azmi BZ, Sadrolhosseini AR, Zaidan AW, Mahdi MA. Preparation of silver nanoparticles in virgin coconut oil using laser ablation. Int J Nanomedicine. 2010;6:71-75.

4. Zamiri R, Zakaria A, Abbastabar Ahangar H, Sadrolhosseini AR, Mahdi MA. Fabrication of silver nanoparticles dispersed in palm oil using laser ablation. Int J Mol Sci. 2010;11:4764-4770.

5. Takami A, Kurata H, Koda S. Laser-induced size reduction of noble metal particles. J Phys Chem B. 1999;103:1226-1232.

6. Kamat PV, Flumiani M, Hartland GV. Picosecond dynamics of silver nanoclusters. Photoejection of electrons and fragmentation. $J$ Phys Chem B. 1998;102:3123-3128.

7. Fujiwara H, Yanagida S, Kamat PV. Visible laser induced fusion and fragmentation of thionicotinamide-capped gold nanoparticles. J Phys Chem B. 1999;103:2589-2591.

8. Ahmadi TS, Logunov SL, El-Sayed MS. Picosecond dynamics of colloidal gold nanoparticles. J Phys Chem. 1996;100:8053-8056.

9. Link S, Mohamed MB, Nikoobakht B, El-Sayed MA. Laser photothermal melting and fragmentation of gold nanorods: Energy and laser pulse-width dependence. J Phys Chem. 1999;103:1165-1170.

10. Mafune F, Kohno JY, Takeda Y, Kondow T. Formation of gold nanonetworks and small gold nanoparticles by irradiation of intense pulsed laser onto gold nanoparticles. J Phys Chem B. 2003;107: 12589-12596.
11. Mafune F. Structure diagram of gold nanoparticles in solution under irradiation of UV pulse laser. Chem Phys Lett. 2004;397:133-137.

12. Tsuji T, Watanabe N, Tsuji M. Laser induced morphology change of silver colloids: Formation of nano-size wires. Appl Surf Sci. 2003;211: 189-193.

13. Chandrasekharan N, Kamat PV, Hu J, Jones G. Dye-capped gold nanoclusters: Photoinduced morphological changes in gold/rhodamine 6G nanoassemblies. J Phys Chem B. 2000;104:11103-11109.

14. Kamat PV. Photophysical, photochemical and photocatalytic aspects of metal nanoparticles. $J$ Phys Chem B. 2002;106:7729-7744.

15. Evanoff DD Jr, Chumanov G. Size-controlled synthesis of nanoparticles. 2. Measurement of extinction, scattering, and absorption cross sections. J Phys Chem B. 2004;108:13957-13962.

16. Tilaki RM, Iraji Zad A, Mahdavi SM. Size, composition and optical properties of copper nanoparticles prepared by laser ablation in liquids. Appl Phys A. 2006;84:415-419.

17. Liao J, Zhang Y, Yu W, et al. Linear aggregation of gold nanoparticles in ethanol. Colloid Surf A. 2003;223:177-183.
International Journal of Nanomedicine

\section{Publish your work in this journal}

The International Journal of Nanomedicine is an international, peerreviewed journal focusing on the application of nanotechnology in diagnostics, therapeutics, and drug delivery systems throughout the biomedical field. This journal is indexed on PubMed Central, MedLine, CAS, SciSearch ${ }^{\circledR}$, Current Contents ${ }^{\circledR} /$ Clinical Medicine,

\section{Dovepress}

Journal Citation Reports/Science Edition, EMBase, Scopus and the Elsevier Bibliographic databases. The manuscript management system is completely online and includes a very quick and fair peer-review system, which is all easy to use. Visit http://www.dovepress.com/ testimonials.php to read real quotes from published authors. 